\title{
TEORIA CRÍTICA E EDUCAÇÃO POLÍTICA EM THEODOR ADORNO
}

\author{
Luiz Roberto Gomes ${ }^{1}$ \\ UFSCar
}

\section{RESUMO}

No atual cenário de complexidade das sociedades contemporâneas, vários são os fatores que contribuem para o agravamento da crise social. O esvaziamento da esfera pública e o conseqüente distanciamento da sociedade civil dos temas eminentemente sociais e humanos são sintomas que evidenciam a crise de uma das dimensões vitais da sociedade, a política. A esse respeito, as reflexões de Theodor Adorno sobre a educação, pensadas no contexto mais amplo de uma sociedade em que prevalece a racionalidade instrumental, o poder ideológico da indústria cultural e a conversão da Bildung (formação cultural) em Halbbildung (semiformação), não deixam dúvidas quanto aos limites do processo formativo atual. A dimensão crítica da cultura, que deveria garantir a emancipação, se desvincula da ação social e acaba cedendo lugar a forma dominante da consciência social voltada para a adaptação e o conformismo. Daí a necessidade, em termos políticos, de uma educação que privilegie a auto-reflexão crítica sobre o processo de semiformação da sociedade, em que ela necessariamente se converteu, já que a determinação política da educação decorre exatamente da necessidade de formação de sujeitos emancipados e livres da condição de alienação social.

Palavras-chave: Teoria Crítica; Educação Política; Theodor Adorno

\section{CRITICAL THEORY AND EDUCATION POLITICS IN THEODOR ADORNO}

\begin{abstract}
In the current scenario complexity of contemporary societies, there are several factors that contribute to the worsening social crisis. The emptying of the public sphere and the consequent alienation of civil society in social and human themes are essentially symptoms of the crisis showed that one of the vital dimensions of society, politics. In this respect, Adorno's reflections on education, conceived in the broader context of a society in which instrumental rationality prevails, the ideological power of the cultural industry and the conversion of Bildung (cultural formation) in Halbbildung (semiformation), nevertheless doubts as to the limits of current training process. The critical dimension of culture, which should ensure the emancipation of social action to relieve and eventually giving way to the dominant form of social consciousness toward adaptation and conformism. Hence the need, in political terms, an education that promotes self-critical reflection on the process of semi-formation of society, it necessarily became, as the political education takes place in exactly the training needs of individuals and emancipated free of the condition of social alienation.

Keywords: Critical Theory, Education Politics, Theodor Adorno
\end{abstract}




\section{Introdução}

Nos dias de hoje, para além do discurso em prol da liberdade e da democratização do saber, é cada vez mais comum encontramos pessoas enclausuradas em si mesmas, sem uma preocupação explícita com as questões que envolvem o "bem comum", ou a vida política. No plano cultural, a privatização dos mecanismos de controle ideológico da informação tem contribuído cada vez mais para que haja a intensificação daquilo que Adorno e Horkheimer, em 1947, denominaram de Indústria Cultural. Isso quer dizer que vivemos em um contexto complexo marcado por profundos dilemas culturais, políticos e econômicos que exigem, do ponto de vista filosófico e da teoria social, uma análise abrangente sobre o que de fato está ocorrendo na sociedade contemporânea.

Estaríamos diante de um processo de despolitização da sociedade atual? Que lugar ainda restaria para a "esfera pública", se as "políticas" continuarem a expressar muito mais os interesses privados do que os efetivamente públicos? A educação política não teria mais sentido, principalmente numa sociedade em que prevalece a lógica sistêmica do dinheiro e do poder?

É nesse contexto de sobreposição do "privado" sobre o "público" e do reducionismo da formação à sua dimensão técnico-instrumental, que propomos à luz da Teoria Crítica da Sociedade, uma reflexão sobre o sentido político da educação. A política, enquanto dimensão vital da sociedade, que compunha a essência da Paidéia grega (formação integral do homem) e do ideário moderno da Bildung (formação cultural), encontra-se hoje eclipsada no interior de uma concepção de sociedade, em que impera, de forma reducionista, a dimensão privativa, administrativa e gerencial da política. Essa forma de conceber a sociedade tem gerado o esvaziamento da "esfera pública" e o conseqüente distanciamento da "sociedade civil" dos temas eminentemente sociais e humanos. É nesse contexto, que colocamos em questão o próprio sentido da educação, com o propósito de discutir os seus fundamentos e os rumos da educação contemporânea.

Recorrer à Teoria Crítica da Sociedade na denominação assumida pela Escola de Frankfurt, como recurso teórico-metodológico, parece ser uma alternativa viável para o enfrentamento dessa questão, principalmente pela possibilidade de referenciar, numa tradição teórica sedimentada, a atitude crítico-educativa necessária para a realização de um projeto de emancipação social. Com tal propósito, estaremos recorrendo ao pensamento de Theodor W. Adorno, como forma de subsidiar teoricamente a reflexão proposta. Ressaltase, que o pensamento de Adorno exerceu e continua exercendo forte influência sobre os diversos estudos realizados por pesquisadores brasileiros, e que fazem de alguma forma, a aproximação entre Teoria Crítica e Educação.

\section{A Teoria Crítica de Theodor Adorno}

Segundo Nobre (2004) a Teoria Crítica da Sociedade é um termo que foi empregado pela primeira vez por Max Horkheimer, em um artigo intitulado "Teoria Tradicional e Teoria Crítica" e publicado em 1937 pelo Instituto de Pesquisa Social em Frankfurt na Alemanha. Trata-se de uma expressão que designa pelo menos três sentidos diferentes: um campo teórico, um grupo específico de intelectuais do Instituto de Pesquisa Social de Frankfurt filiados a esse campo teórico e a Escola de Frankfurt.

Independente do sentido que se possa atribuir à Teoria Crítica da Sociedade, o sentido clássico do conceito de Teoria Crítica, tal como fora empregado por Horkheimer 
em 1937, evidencia os dois princípios fundamentais que demarcam um campo teórico específico: a orientação para a emancipação e o comportamento crítico. Esses princípios são explicitados pelo autor, no momento em que ele confronta dois modelos distintos de teoria social: a "teoria tradicional", que em nome de uma pretensa neutralidade científica, acaba prevalecendo a descrição do funcionamento da sociedade e a adaptação do pensamento à realidade; e a "teoria crítica", que considera o conhecimento na dialética da prática transformadora das relações sociais vigentes, apresentando criticamente "as coisas como são" e "como poderiam ser", por intermédio da reflexão sobre as potencialidades e obstáculos à emancipação. Tal como expõe Nobre:

Os dois princípios mostram a possibilidade de a sociedade emancipada estar inscrita na forma atual de organização social como uma tendência real de desenvolvimento, cabendo à teoria o exame do existente não para descrevê-lo simplesmente, mas para identificar e analisar a cada vez os obstáculos e as potencialidades de emancipação presentes em cada momento histórico. (NOBRE, 2004, p. 33-34).

Esse imperativo crítico-emancipatório explicitado em forma de princípios, e que acabou sendo a "marca" da Teoria Crítica, se constitui como tradição intelectual, desde a fundação do Instituto de Pesquisa Social, por Felix Weil em 1923, em Frankfurt na Alemanha. A Escola de Frankfurt, outra forma de denominação da Teoria Crítica, nada mais é do que um grupo interdisciplinar de intelectuais, de diversas áreas (filosofia, sociologia, economia, psicologia, música, entre outras), vinculados ao Instituto de Pesquisa Social de Frankfurt, e que tinha como principal objetivo promover investigações científicas, de natureza crítica, sobre os processos imanentes de dominação da sociedade, além dos obstáculos e as possibilidades efetivas de emancipação social (BRONNER, 1997; NOBRE, 2004 e NOBRE 2008).

Segundo (BRONNER, 1997; NOBRE, 2004 e JAY, 1996) entre os autores vinculados a essa tradição intelectual, podemos destacar: Karl Korsch (1890-1961), Friedrich Polock, (1894-1970), Walter Benjamin (1892-1940), Max Horkheimer (18951973), Theodor W. Adorno (1903-1969), Herbert Marcuse (1898-1979), Franz Neumann (1900-1954), Eric Fromm (1900-1980) que muito contribuíram para a solidificação da Teoria Crítica; e Jürgen Habermas (1929-) professor aposentado da Universidade de Frankfurt que continua, juntamente com Axel Honneth (1949-) e muitos outros autores desconhecidos, preservando em suas pesquisas, os princípios que definem o sentido originário desse campo teórico específico. Naturalmente que não se trata de uma concepção unívoca de Teoria Crítica, mas de sentidos peculiares atribuídos a cada investigação de fenômenos diversos da sociedade.

Com o propósito de continuar o grande empreendimento intelectual do Instituto de Pesquisa Social de Frankfurt, e tendo como seu principal parceiro o pesquisador Max Horkheimer, Theodor W. Adorno (filósofo, sociólogo, musicólogo e crítico da cultura) publicou, juntamente com Horkheimer, o livro Dialética do Esclarecimento em 1947, e este fato pode ser considerado o marco representativo de uma mudança de orientação no próprio sentido da teoria crítica (BRONNER, 1997).

Nesse livro, que se inicia com uma reflexão sobre o conceito de esclarecimento, sucedido por dois "excursos", um ensaio sobre a indústria cultural, e uma análise do antsemitismo; os autores abandonam o modelo do materialismo interdisciplinar da década de 1930, o que significa, sob muitos aspectos, abandonar também alguns elementos decisivos da Teoria Crítica, tal como apresentada em 1937 por Horkheimer em "Teoria Tradicional e 
Teoria Crítica". Sobre essa mudança de orientação, Marcos Nobre consegue apresentar uma síntese muito esclarecedora, que reproduziremos a seguir:

O modelo do materialismo interdisciplinar tinha por pressuposto fundamental que o capitalismo produz não apenas a ilusão de uma sociedade de livres e iguais, mas também a possibilidade concreta de realização da igualdade e da liberdade. Desse modo, em 'Teoria Tradicional e Teoria Crítica', a possibilidade da prática transformadora encontrava-se bloqueada historicamente pela repressão e pela propaganda nazista, mas permanecia ainda no horizonte a idéia de que as possibilidades de intervenção transformadora no mundo poderiam se reabrir com a derrota do nazismo (NOBRE, 2004, p. 49).

E continua,

Esse não foi, entretanto, o diagnóstico de Horkheimer e Adorno no período pós-guerra. A vitória das tropas aliadas não significou, para eles, a restauração das possibilidades revolucionárias. Pelo contrário, o diagnóstico do tempo presente que desenvolveram na Dialética do Esclarecimento foi um bloqueio estrutural da prática transformadora. Esse diagnóstico estava calcado em análises econômicas (de Friedrich Pollock mais uma vez, a quem foi dedicado o livro de 1947) que apontavam para uma mudança estrutural do funcionamento do capitalismo, na qual a intervenção do Estado na organização da produção, distribuição e consumo tinha adquirido o caráter de um verdadeiro planejamento (...) Essa nova forma de capitalismo foi denominada por Pollock 'capitalismo de Estado', sendo que, na Dialética do Esclarecimento, Horkheimer e Adorno elaboraram uma versão própria dessa conceituação de Pollock, que chamaram de 'capitalismo administrado' ou 'mundo administrado' (NOBRE, 2004, p. 49-50 - grifos do autor).

O que fica evidenciado nessa mudança de orientação é que as fases anteriores do capitalismo, em especial a monopolista ou de Estado, como diria Pollock, que apontavam para além de si mesmas, o campo de ação capaz de abolir o capital e instaurar a sociedade justa, já não são percebidos da mesma forma no diagnóstico de Adorno e Horkheimer da Dialética do Esclarecimento. Trata-se agora, de um capitalismo administrado, ou seja, de um sistema que se fecha em si mesmo e que, portanto, bloqueia estruturalmente qualquer possibilidade de superação da dominação pela via da ação transformadora ou emancipatória da razão iluminista. A grande novidade é que não se trata mais de um sistema econômico auto-regulado pelo mercado, mas de um sistema controlado de fora, por forças políticas que penetram na cultura e acabam agindo de forma sutil na burocracia "instrumental" do capitalismo. Como esclarece Marcos Nobre:

Historicamente, o grande projeto de emancipação da razão humana esteve sempre colocado na determinação racional dos fins, ou seja, no debate e na efetivação daqueles valores julgados belos, justos e verdadeiros. No capitalismo administrado, a razão se vê reduzida a uma capacidade de adaptação a fins previamente dados de calcular os melhores meios para alcançar fins que lhe são estranhos. Essa racionalidade é dominante na sociedade não apenas por moldar a economia, o sistema político ou a burocracia estatal, ela também faz parte da socialização, do processo de 
aprendizado e da formação da personalidade (NOBRE, 2004, p. 51 grifos do autor).

Esta foi a principal razão para que Adorno e Horkheimer realizassem uma investigação específica sobre os processos de racionalidade que estruturavam a sociedade, no contexto dos anos 1940. Esse estudo resultou na Dialética do Esclarecimento de 1947, e que teve como principal objetivo, buscar compreender porque a racionalidade das relações sociais humanas, ao invés de levar à instauração de uma sociedade de mulheres e homens livres e iguais, acabou por produzir um sistema social conformista que bloqueou estruturalmente a principal via de emancipação: a razão iluminista. Particularmente para Adorno, a Dialética do Esclarecimento tem um sentido teórico-crítico próprio, pois se trata da negação crítica da visão racionalista, idealista e progressista da história que se firmava como teoria hegemônica da sociedade burguesa, aspecto este que é retomado mais tarde na Dialética Negativa (1967), em que toda visão sistêmica e totalizante da sociedade é absolutamente rejeitada.

Adorno tem uma vasta produção de pesquisa sobre diversos temas relacionados à crítica da indústria cultural e as possibilidades e/ou impossibilidades de emancipação social. São várias obras publicadas ${ }^{2}$, ainda não mencionadas nesse artigo, e que denotam um sentido próprio para a definição dos fundamentos que norteiam a sua concepção de Teoria Crítica da Sociedade, das quais se destacam: A atualidade da filosofia (1931), A idéia da história natural (1932), A situação social da música (1932), Estudos sobre autoridade e família (1936), Caráter fetichista da música e a regressão da audição (1938), Sobre música popular (1941), Dialética do Esclarecimento (1944/1947)², Mínima Morália (1947), A personalidade autoritária (1950), Prismas (1955), Notas de literatura (1958), A polêmica dos positivistas na sociologia alemã (1961), Introdução a sociologia da música (1962), Intervenção:novos modelos críticos (1963), A educação após Auschwitz. (1965), Dialética Negativa (1967), Educação e Emancipação (1969), Teoria Estética (1970).

Esta vasta produção bibliográfica indica que Adorno elege um objeto específico de análise, a cultura, a fim de dar a sua contribuição ao projeto da Teoria Crítica da Sociedade. Poderíamos dizer, em resumo, que o pensamento teórico-crítico de Adorno focaliza-se na crítica (negação) de todo e qualquer processo de alienação do sujeito, mediatizado pela indústria cultural e que conduz a sociedade para um estado de profunda barbárie. Como nos esclarece Wolfgang Leo Maar, o foco da Teoria Crítica em Adorno:

[...] Não se baseia em uma idealização a ser realizada, mas se apóia na decifração crítica do presente já realizado e se realizando, no processo de reprodução apreendido como construção material histórica determinada em sua forma social, num contexto de continuidade. A cultura tematizada no presente já não seria apreendida como ideal emancipadora, mas real conservadora ou 'afirmativa'. Como resultado, legitimaria a sociedade imperante, que reconstrói como 'cópia' ordenada de modo estritamente afirmativo (MAAR, 2003, p.3).

O que fica claro na concepção de teoria crítica de Adorno, é que não faz mais sentido uma teoria emancipadora da consciência de classe proletária, tal como foi pensada por Lukács (1975), que a entendida como construção ideal-típica a orientar a intervenção social rumo à libertação do modo de reprodução vigente. Esta seria substituída, por Adorno, pela teoria crítica da semiformação da classe burguesa vigente, decifrada em sua forma social determinada, entre outras coisas, como ordenamento de adequação, de sujeição aos termos existentes da reprodução social. 
Assim, a grande questão imposta por Adorno seria: como emancipar o sujeito desse processo de manipulação e escravização cultural? A saída apontada por ele, para esse processo de alienação e enclausuramento do sujeito, estará condicionada aos processos formativos (educacionais) capazes de proporcionar uma condição política, estética e cultural diferenciada. O grande desafio será: "esclarecer" e "emancipar" o sujeito do conformismo a que está submetido pela semiformação e indústria cultural. Tal questão será o objeto principal das análises subseqüentes ${ }^{4}$.

\section{A Educação Política em Theodor Adorno}

Para que possamos explicitar, com maior propriedade, o sentido da educação política em Adorno, que pode ser traduzido pela crítica à disposição educativa de se adaptar "cegamente" a condição social vigente, alguns conceitos centrais de sua teoria devem ser ressaltados, tais como: indústria cultural, Halbbildung (semiformação), Bildung (formação cultural), educação e emancipação, que serão abordados aqui com o propósito de subsidiar a compreensão crítica do sentido político da educação adorniana.

$\mathrm{Na}$ Dialética do Esclarecimento, Adorno e Horkheimer apresentam, com significativa lucidez, uma análise sobre a caracterização social objetiva da perda da dimensão emancipatória, gerada na dialética da razão. Dessa forma, tal como assinalada por Wolfgang Leo Maar "A Dialética do Esclarecimento constitui a expressão da subjetividade ameaçada, a 'semiformação', e das forças anônimas que ameaçam a subjetividade, a 'indústria cultural'” (MAAR, 1995, p. 20).

Como podemos notar a percepção crítica de Adorno e Horkheimer, em estabelecer um diagnóstico preciso sobre o processo de regressão do esclarecimento à ideologia, mediante a "mistificação das massas" e conversão das pessoas em "objeto de dominação", ocorre num estágio de significativo progresso do Aufklärung (esclarecimento), que para Kant (1985) significava uma condição para a emancipação. Mas como uma sociedade altamente desenvolvida em termos de esclarecimento poderia ser tutelada e dominada pela própria "cultura"? Aqui está o grande mérito da Dialética do Esclarecimento, ao submeter à crítica a condição de uma sociedade supostamente esclarecida, tal como registrado pelos próprios autores, logo no início do livro:

No sentido mais amplo do progresso do pensamento, o esclarecimento tem perseguido sempre o objetivo de livrar os homens do medo e de investi-los na posição de senhores. Mas a terra totalmente esclarecida resplandece sob o signo de uma calamidade triunfal (ADORNO e HORKHEIMER, 1985, p. 19).

Os autores constatam que a "sociedade totalmente esclarecida" não passa de uma "sociedade administrada", e nessa, os indivíduos se vêem completamente anulados em face do poder econômico, da visão utilitária e da racionalidade técnico-instrumental, que impinge à sociedade a sua condição de alienação e enclausuramento.

Com o conceito de indústria cultural, Adorno e Horkheimer esclarecem que há um processo de imposição da estrutura social, tal como concebido pelo modo de produção capitalista, e que descobre na face instrumental do esclarecimento, e na racionalidade técnica, a forma sutil de reificar a cultura, e transformá-la em cultura de massa. Ela manipula as necessidades sociais, através de um processo de "integração e assimilação voluntária" das pessoas em uma suposta "ordem" estabelecida, como se fosse única. É 
nisso que consiste o caráter ideológico da indústria cultural: reificar a práxis social com as formas de integração da cultura. No caso específico da educação, Adorno esclarece:

Em um mundo onde a educação é um privilégio e o aprisionamento da consciência impede de toda maneira o acesso das massas à experiência autêntica das formações espirituais, já não importam tanto os conteúdos ideológicos específicos, mas o fato de que simplesmente haja algo preenchendo o vácuo da consciência expropriada e desviando a atenção do segredo conhecido por todos (ADORNO, 1998, p. 20).

Na Teoria da Semicultura, Adorno enfatiza a necessidade de se construir uma teoria abrangente, que transcenda a simplificação pedagógica, e que seja capaz de diagnosticar a crise da formação cultural manifestada - na onipresença do espírito alienado - pela forma generalizada de conversão da Bildung (formação cultural) em Halbbildung (semiformação). Nas palavras do autor:

Apesar de toda ilustração e de toda informação que se difunde (e até mesmo com sua ajuda) a semiformação passou a ser a forma dominante da consciência atual (...) a formação nada mais é que a cultura tomada pelo lado de sua apropriação subjetiva (...) ela tem um duplo caráter: remete à sociedade e intermedia esta e a semiformação (ADORNO, 1996, p. 389).

Para Adorno, é no processo de reprodução material da sociedade que é possível captar a dialética da "formação" e da "semiformação". Na sociedade contemporânea, a significação germânica da Bildung, especialmente na acepção da "liberdade", dos "valores" que orientavam a razão prática, foi reduzida a discursos ideológicos, desvinculados da ação social. Com isso, a promessa da emancipação e da autonomia, que era a principal razão do ideal iluminista moderno, foi solapada e substituída pela adaptação e submissão disciplinada à lógica da dominação. Assim, a dimensão crítica da cultura, que deveria garantir a emancipação, cede lugar à semiformação, em que predomina a racionalidade instrumental voltada para a adaptação e o conformismo à situação vigente.

Essa condição social de conversão da cultura em pseudocultura chega a travar a realização da autêntica experiência formativa, a ponto de Adorno dizer que: "a única possibilidade que resta à cultura é auto-reflexão crítica sobre a semiformação, em que necessariamente de converteu" (ADORNO, 1996, p. 410). Essas considerações de Adorno sobre a condição social da semicultura e a necessidade da auto-reflexão crítica sobre a semiformação, são fundamentais para a compreensão do sentido político da educação.

Os ensaios de Adorno sobre a educação, e que estão reunidos no livro Educação e Emancipação (1995) são claros quanto aos limites e possibilidades da educação no contexto semiformação. No ensaio Educação - Para quê? Adorno explicita a sua concepção de educação:

... concebo como sendo educação (...) não a assim chamada modelagem de pessoas, porque não temos o direito de modelar pessoas a partir do seu exterior; mas também não a mera transmissão de conhecimentos, cuja característica de coisa morta já foi mais do que destacada, mas a produção de uma consciência verdadeira. Isto seria inclusive da maior importância política; sua idéia, se é permitido dizer assim, é uma exigência política (...) uma democracia com o dever de não apenas funcionar, mas operar conforme seu conceito, demanda pessoas emancipadas. Uma democracia efetiva só pode ser imaginada enquanto 
uma sociedade de quem é emancipado (ADORNO, 1995a, p. 141-142; grifos meus).

Como podemos observar Adorno foca o sentido político da educação na produção de uma consciência verdadeira, ao se contrapor criticamente, à condição social de mera adaptação e conformismo à situação vigente. É nesse contexto que a indústria cultural forma, pela ideologia da semicultura, uma consciência falsa da realidade social. Daí a necessidade da formação de uma consciência desalienada, e politicamente emancipada.

Esclarecido o conceito de educação e o sentido político da educação emancipatória, Adorno nos adverte sobre a necessidade da reflexão crítica das possibilidades de emancipação, a partir do condicionamento social da própria cultura. No ensaio Crítica Cultural e Sociedade, de 1969, ele salienta que, hoje a sociedade ela própria é sua ideologia, ou seja, uma forma de sociedade determinada conforme certo modelo de produção social dos homens, de modo que a apreensão do conteúdo dessa ideologia passará necessariamente pela análise crítica do condicionamento social vigente. É por isso que a emancipação não pode ser idealizada de forma ingênua, pelo contrário, ela precisa ser concebida no bojo do próprio ordenamento social. Dessa forma, Adorno destaca, textualmente, os dois problemas relacionados à emancipação:

Penso, sobretudo, em dois problemas difíceis que é preciso levar em conta quando se trata de emancipação. Em primeiro lugar, a própria organização do mundo em que vivemos e a ideologia dominante - hoje muito pouco parecida com uma determinada visão de mundo ou teoria ou seja, a organização do mundo converteu-se a si imediatamente em sua própria ideologia. Ela exerce uma pressão tão intensa sobre as pessoas que supera toda educação. (...) No referente ao segundo problema (...) emancipação significa o mesmo que conscientização, racionalidade (ADORNO, 1995a, p. 143).

Adorno insiste na ideia de que é necessário decifrar as condições sociais que determinam o modo de ser dos homens, por intermédio da reflexão racional "conscientização" - das condições de produção da realidade social. Aqui reside um dos elementos fundamentais da emancipação política, a saber, a contradição que a impede a conciliação total. Como diria Adorno, no ensaio Tempo Livre (1969): "É evidente que ainda não se alcançou inteiramente a integração da consciência (...). Os interesses reais do indivíduo ainda são suficientemente fortes para, dentro de certos limites, resistirem à apreensão" (ADORNO, 1995b, p. 81).

Se não há a integração total da sociedade, devido à própria contradição social, que funciona como o antídoto da semiformação, então continua existindo a possibilidade de emancipação. Essa questão foi abordada por Adorno, no último ensaio do livro Educação $e$ Emancipação: "... é preciso começar a ver efetivamente as enormes dificuldades que se opõem à emancipação nesta organização do mundo (...). O motivo é a contradição social" (ADORNO, 1995a, p. 181).

Como podemos notar a educação emancipatória não se sustenta pela retórica e sim pela crítica das condições objetivas que promovem a semiformação, ou seja, pela identificação da contradição social que bloqueia a aptidão para a experiência formativa autônoma - Bildung, sendo esta substituída, de forma "natural" pela configuração heterônoma de formação - Halbbildung. É por essa razão fundamental que Adorno (1995a, p. 183) salienta que "a única concretização efetiva da emancipação consiste em que aquelas poucas pessoas interessadas nessa direção orientem toda sua energia para que a 
educação seja uma educação para a contradição e para a resistência". E isso seria plenamente possível, se conseguíssemos, por exemplo, mostrar aos alunos as "ideologias" presentes na vida da sociedade culturalmente construída, além do "despertar da consciência" quanto aos enganos a que somos submetidos, permanentemente, no interior da própria cultura. Trata-se, de uma crítica inerente ao próprio condicionamento social e suas contradições. É assim que Adorno identifica, no provimento da consciência do condicionamento social, o potencial crítico da educação. Nas suas palavras:

É necessário contrapor-se a uma tal ausência de consciência, é preciso evitar que as pessoas golpeiem para os lados sem refletir a respeito de si próprias. A educação tem sentido unicamente como educação dirigida a uma auto-reflexão crítica (ADORNO, 1995a, p. 121. grifo meu).

É dessa forma, que se configura o sentido político da educação em Adorno, promovida pela auto-reflexão crítica do condicionamento social, mediante a consciência pública das contradições que geram o enclausuramento do sujeito. Trata-se de uma educação negativa ${ }^{5}$, que realiza a crítica à forma ideológica de prover a semicultura, desobstruindo, dessa forma, o caminho para a realização da experiência formativa, e consequentemente da emancipação.

\section{Considerações finais}

A Teoria Crítica da Sociedade, na forma como a apresentamos aqui, continua fornecendo os elementos necessários para realização da crítica social contemporânea. A orientação para a emancipação, que fundamenta o pensamento de Theodor Adorno é um exemplo claro de que ainda há espaço para as reflexões dessa natureza. Acreditamos ainda, que a Teoria Crítica continua sendo extremamente fecunda para as reflexões no campo educacional, especialmente, na análise dos limites e possibilidades de um projeto emancipatório de formação social. Foi com esse referencial teórico, que procuramos desenvolver uma reflexão específica sobre o vínculo necessário entre educação e política, e que parece estar bem distante dos projetos educacionais atuais.

Como vimos, a partir do pensamento teórico-crítico de Adorno, numa sociedade em que prevalece a racionalidade técnico-instrumental e o poder ideológico da indústria cultural, a dimensão crítica da cultura, que deveria garantir a emancipação, se desvincula da ação social e acaba cedendo lugar a Halbbildung, que passa a ser a forma dominante da consciência social voltada para a adaptação e o conformismo. Daí a necessidade, em termos emancipatórios, de uma educação que privilegie a auto-reflexão crítica sobre o processo de semiformação da sociedade, em que ela necessariamente se converteu.

O sentido político da educação decorre exatamente da necessidade de formação de sujeitos emancipados, livres da condição de alienação e enclausuramento social. Como nos alerta Zygmunt Bauman, a formação política que poderia garantir uma condição emancipatória para a sociedade contemporânea, esbarra em inúmeras dificuldades, principalmente:

[...] Considerando o perigoso estado atual da esfera público-privada, da qual 'o público' recuou para buscar abrigo em lugares politicamente inacessíveis e o 'privado' está a ponto de retirar-se para a própria autoimagem. Para adaptar a Ágora aos indivíduos livres e à sociedade livre, é preciso interromper ao mesmo tempo sua privatização e despolitização. É preciso restabelecer a tradução do privado para o público. É preciso 
retomar (na Ágora e não apenas em seminários de filosofia) o discurso interrompido do bem comum - que torna a liberdade individual tanto factível como digna de luta (BAUMAN, 2000, p. 113).

Essas reflexões não tiveram outro objetivo, senão o de tentar retomar o debate sobre a dimensão política da educação, que no passado recente ocupou o centro de várias teorias educacionais no Brasil, especialmente àquelas que traduziam uma das principais teses de Paulo Freire (1980), de que a "educação é um ato político". Não se trata de um discurso nostálgico, mas de resistência à forma como "privado" tem suplantado as instâncias de formação cultural do "bem comum".

Finalizando, não poderia deixar de registrar uma das compreensões mais lúcidas que tive oportunidade de conhecer no livro A dignidade da política de Hannah Arendt, e que traduz, de forma ampliada, o meu propósito de reflexão nesse artigo: "o sentido da política é a liberdade" (ARENDT, 1993, p. 117).

\section{Referências bibliográficas}

ADORNO, Theodor W. Prismas: crítica cultural e sociedade. Trad. Augustin Wernet e Jorge Mattos Brito de Almeida. São Paulo: Editora Ática, 1998.

ADORNO, Theodor W. Teoria da Semicultura. Trad. Newton Ramos de Oliveira, Bruno Pucci e Cláudia B. M. de Abreu. Educação e Sociedade: revista quadrimestral de ciência da educação, ano XVII, No. 56, dezembro/96. Campinas: Editora Papirus, 1996.

ADORNO, Theodor W. Educação e Emancipação. Trad. Wolfgang Leo Maar. Rio de Janeiro: Editora Paz e Terra, 1995a.

ADORNO, Theodor W. Tempo Livre. ADORNO, Theodor W. Palavras e Sinais: modelos críticos 2. Trad. Maria Helena Ruschel. Petrópolis: Editora Vozes, 1995 b.

ADORNO, Theodor W. Dialética Negativa. Trad. José Maria Ripalda. Madrid: Editora Taurus, 1975.

ADORNO, Theodor W; FRENKEL-BRUNSWIK, Else; LEVINSON, Daniel J; SANFORD, R. Nevitt. La Personalidad Autoritária. Trad. Dora Aída Cymbler. Buenos Aires: Ed. Proyección, 1965.

ADORNO, Theodor W e HORKHEIMER, Max. Dialética do Esclarecimento: fragmentos filosóficos. Trad. Guido Antonio de Almeida. Rio de Janeiro: Editora Jorge Zahar, 1985.

ARENDT, Hannah. A Dignidade da Política. Trad. Helena Martins e outros. Rio de Janeiro: Relume-Dumará, 2002.

BAUMAN, Zygmunt. Em Busca da Política. Trad. Marcus Penchel. Rio de Janeiro: Jorge Zahar Editor, 2000.

BRONNER, Stephen Eric. Da Teoria Crítica e seus Teóricos. Campinas: Papirus, 1997.

CULLEN, Carlos. Perfiles ético-políticos de La educación. Buenos Aires: Paidós, 2008.

FREIRE, Paulo. A Pedagogia do Oprimido. Rio de Janeiro: Editora Paz e Terra, 1980.

JAY, Martin. As idéias de Adorno. Trad. Adail Ubirajara Sobral. São Paulo: Cultrix/Editora da Universidade de São Paulo, 1988.

JAY, Martin. La Imaginacion Dialectica. Trad. Juan Carlos Curutchet. Madrid: Taurus, 1996. 
KANT, Immanuel. Resposta à pergunta: que é esclarecimento? In: Textos Seletos (edição bilíngüe). Trad. Francisco de Sousa Fernandes. Petrópolis: Editora Vozes, 1985.

LUKÁCS, Georg. Historia y consciencia de clase. Trad. Manuel Sacristán. Barcelona: Ediciones Grijalbo, 1975.

MAAR, Wofgang Leo. À guisa de introdução: Adorno e a experiência formativa. In: ADORNO, Theodor W. Educação e Emancipação. Rio de Janeiro: Editora Paz e Terra, 1995.

MAAR, Wofgang Leo. Adorno, Semiformação e Educação. In: Revista Educação e Sociedade. V. 4, n.83. Campinas, agosto de 2003.

NOBRE, Marcos. Curso Livre de Teoria Crítica. Campinas: Papirus, 2008.

NOBRE, Marcos. A Teoria Crítica. Rio de Janeiro: Jorge Zahar Editor, 2004.

PUCCI, Bruno; ALMEIDA, Jorge; LASTÓRIA, Luiz A. Calmon Nabuco. Experiência Formativa e Emancipação. São Paulo: Nankin Editorial, 2009.

PUCCI, Bruno. Filosofia Negativa e Educação: Adorno. In: Filosofia, Sociedade e Educação. Marília: UNESP, ano 1, nº 1, 1997.

ZUIM, Antônio Álvaro Soares; PUCCI, Bruno; RAMOS DE OLIVEIRA, Newton. Adorno: o poder educativo do pensamento crítico. Petrópolis: Vozes, 2000.

Notas:

\footnotetext{
${ }^{1}$ Professor do Departamento de Educação e do Programa de Pós-graduação em Educação da UFSCar. Email: luizrgomes@ufscar.br / luizroberto.gomes@gmail.com

2 Para ter acesso às informações completas sobre a biografia e produção bibliográfica de Adorno conferir: JAY, Martin. As idéias de Adorno. Trad. Adail Ubirajara Sobral. São Paulo: Cultrix/Editora da Universidade de São Paulo, 1988; JAY, Martin. La Imaginacion Dialectica. Trad. Juan Carlos Curutchet. Madrid: Taurus, 1996 e ainda ZUIM, Antônio Álvaro Soares; PUCCI, Bruno; RAMOS DE OLIVEIRA, Newton. Adorno: $o$ poder educativo do pensamento crítico. Petrópolis: Vozes, 2000.

3 A obra Dialética do Esclarecimento de Adorno e Horkheimer foi concluída em 1944 e publicada em primeira edição (não comercial) nos Estados Unidos, ainda em 1944. Só em 1947, é que a obra foi publicada e divulgada em edição comercial.

${ }^{4}$ Para uma reflexão mais aprofundada sobre a questão da formação emancipação, conferir os artigos recentes publicados no livro organizado por PUCCI, Bruno; ALMEIDA, Jorge; LASTÓRIA, Luiz A. Calmon Nabuco. Experiência Formativa e Emancipação. São Paulo: Nankin Editorial, 2009.

5 A educação negativa é concebida aqui, segundo o modelo da dialética negativa de Adorno. Cf. Adorno, (1975). Conferir ainda, PUCCI, Bruno. Filosofia Negativa e Educação: Adorno. In: Filosofia, Sociedade e Educação. Marília: UNESP, ano 1, nº 1, 1997.
}

Artigo recebido em: 27/07/10

Aprovado em: 28/08/10

Revista HISTEDBR On-line, Campinas, n.39, p. 286-296, set.2010 - ISSN: 1676-2584 